University of the Pacific

Scholarly Commons

All Faculty Articles - School of Engineering and Computer Science

All Faculty Scholarship

2-1-2015

\title{
Wind turbine rotor fragments: impact probability and setback evaluation
}

Scott M. Larwood

University of the Pacific, slarwood@pacific.edu

C. P. Van Dam

University of California, Davis

Follow this and additional works at: https://scholarlycommons.pacific.edu/soecs-facarticles

Part of the Engineering Commons

\section{Recommended Citation}

Larwood, S. \& van Dam, C.P. Clean Techn Environ Policy (2015) 17: 475. doi:10.1007/s10098-014-0805-9

This Article is brought to you for free and open access by the All Faculty Scholarship at Scholarly Commons. It has been accepted for inclusion in All Faculty Articles - School of Engineering and Computer Science by an authorized administrator of Scholarly Commons. For more information, please contact mgibney@pacific.edu. 


\title{
Wind turbine rotor fragments: impact probability and setback evaluation
}

\author{
by Scott Larwood, University of the Pacific \\ and C. P. van Dam, University of California, Davis
}

June 2014

\begin{abstract}
With increasing installation of wind turbines, the exposure to the hazard of impact from blade fragments increases. Local authorities use setbacks to reduce the risk by limiting the distance from wind turbines to adjacent property lines and dwellings. Unduly conservative setbacks are a deterrent to wind energy development. To determine appropriate setbacks, the authors developed a fragment trajectory model based on fragment rotation and aerodynamics. The model was used to simulate fragment trajectories at various rotor speeds, with randomly generated inputs for wind speed, wind direction, rotor azimuth, and rotor break position. Four sizes of wind turbines were studied, with rated power of $750 \mathrm{~kW}, 1.5$ MW, 3 MW and 5 MW. A sensitivity analysis showed that a fragment trajectory is highly dependent on the input parameters. However, for multiple trajectories from a given turbine and rotor speed, the sensitivity of the impact probability to most inputs was negligible. The results indicate that the range increased with turbine rating and rotor speed. When the range was normalized by overall turbine height, the probability of impact at a particular normalized range decreases with turbine rating. Planning agencies use the normalized range
\end{abstract}


for setbacks, and the results indicate that using a common setback for all turbine sizes would be reasonable. Existing setback standards of 2-3 overall turbine heights offer better than 1 in 1,000,000 probability of impact per year; however, setbacks approaching 1 turbine height will have an order of magnitude higher probability of impact.

Keywords: Wind energy, permitting, hazards 


\section{Introduction}

\section{$1.1 \quad$ Background}

Although in use for centuries, wind power became a provider of utility-scale electricity in the late 1980's (Gipe, 1995). Worldwide installation of wind turbines has grown at an exponential rate, as shown in the latest U.S. Department of Energy report on wind energy (Wiser and Bolinger, 2013). Wind turbines produce the largest percentage of renewable energy in California (6.3\% of total system energy in 2012; the next highest renewable is $4.4 \%$ for geothermal (Nyberg, 2014)).

Wind turbines have become ubiquitous symbols of sustainability, with many societal benefits. However, as with any form of sustainable technology, wind power has associated risks. Huesemann (2003) discusses unavoidable negative environmental impacts of sustainable technologies; for wind power this includes land use and manufacturing wastes. Fritzsche (1989) states that the main risks with wind energy are associated with the equipment manufacture and installation, which compares to environmental risks from battery production and disposal in electric vehicles (Ramoni and Zhang, 2013). However, this work is about risk during the operation phase. A primary hazard of wind turbines during operation is the failure of a portion of the rotor resulting in fragments being thrown from the turbine (Larwood and van Dam, 2006). Due to the rotational speeds of the rotor, the fragments could travel long distances. Dramatic photos and videos of wind turbine failures on the World Wide Web have increased the public visibility of this hazard.

\subsection{Wind Energy Ordinances}

Concerns over public exposure to the rotor fragment hazard led communities to develop setbacks from adjacent property lines and structures/dwellings. In California, the development of these setback ordinances took place in the 1980's (Larwood and van Dam, 2006). In 
general, the setbacks were based on the overall height of the turbines, which is the height to the wind turbine hub plus the length of one blade. A typical setback from a property line with a dwelling is three times the overall turbine height.

Utility-scale, land-based turbines have evolved from $50 \mathrm{~kW}$ machines of 25 meter (m) overall height to $3.0 \mathrm{MW}$ machines of $126 \mathrm{~m}$ overall height. The nature of that evolution, in general, is that manufacturers stopped production of smaller turbines due to improved economics of the new larger turbines. With increased overall height, increased setback distance is required, which constricts development for modern turbines. Because of this restriction, the California Energy Commission asked the authors to study the wind energy permitting issue of safety setbacks, which is reported in Larwood and van Dam (2006). The current work is an outcome of the report recommendations.

\subsection{Analysis of the Rotor Fragment Risk}

In previous studies of rotor fragment risk, the probability of impact for various setback distances was not explicitly evaluated, and would be of limited use to planning officials. Our contribution is the development of methodology that combines (1) a numerical technique to predict the distance a rotor fragment travels based on a range of wind turbine, fragment, and atmospheric parameters and (2) a probability assessment technique. This methodology allows users to determine the probability of an impact by a wind turbine rotor fragment based on the distance from the turbine and the probability of turbine rotor failure. As wind turbines further develop in terms of size and their technology further matures in terms of reliability, this methodology provides authorities a tool to (re-)analyze setback distances for wind turbines in their jurisdiction. A diagram of the analysis methodology is shown in Fig. 1 . 


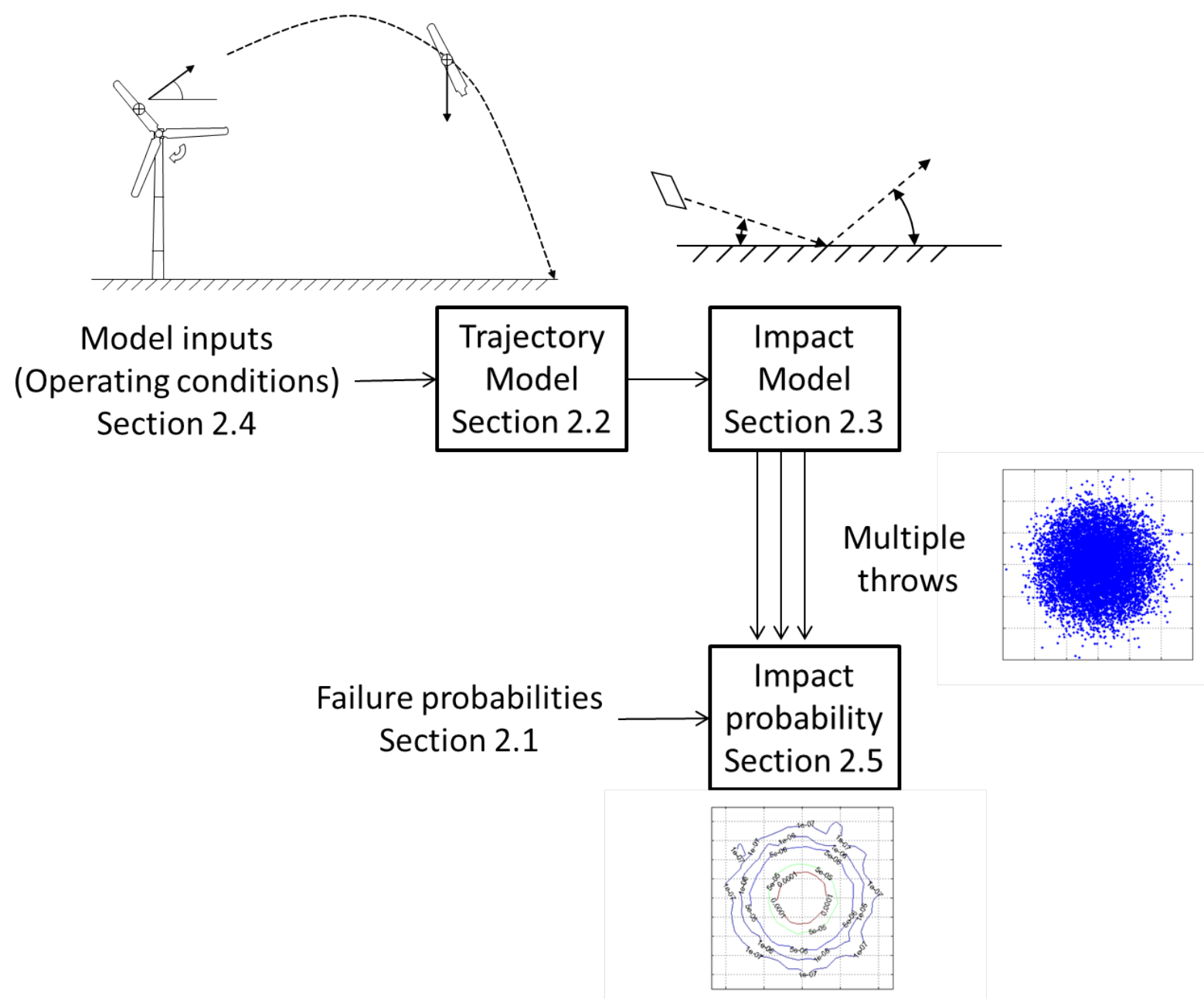

Figure 1: Rotor fragment analysis block diagram

Rotor Failure Probabilities Larwood and van Dam (2006) has details regarding wind turbine rotor failures. The probability of a rotor failure from various studies ranged from $1.2 \times$ $10^{-2}$ (1.2 in 100) per turbine per year to $5.4 \times 10^{-3}$. Braam et al. (2005) (in Dutch, Appendix A translated in Larwood and van Dam (2006)) reports on rotor failure probabilities; the authors determined that these probabilities are the most representative of modern turbines, and are used in the current work.

Fragment Trajectory The analysis starts by computing the trajectory of the fragment after it has been released from the turbine. This work is similar to risk assessment of 
windborne debris (Lin and Vanmarcke, 2008); however, the wind turbine analysis differs due to the momentum (linear and angular) at release. Several authors discussed below have studied the rotor fragment hazard, with the majority of these studies originating from the 1980's when very large multi-MW research turbines were being considered.

The simplest theory is vacuum ballistics (Macqueen et al., 1983), which assumes no aerodynamic friction. Vacuum ballistics is a classic problem in mechanics, with an exact solution. The solution for range $X$ is:

$$
X=\frac{V_{0}^{2}}{g} \sin 2 \theta
$$

where $V_{0}$ is the release velocity, $g$ is gravitational acceleration, and $\theta$ is the release angle. Note that the range is dependent on the release velocity squared and the release angle. The release velocity depends on the rotor rotation speed and the radial location of the fragment mass center. The release angle $\left(0^{\circ}\right.$ is blade at 12 o'clock position) is considered random with uniform probability; $315^{\circ}$ results in maximum range. A large majority of the fragments land near the turbine with $90^{\circ} \leq \theta \leq 270^{\circ}$.

A more complex model is drag ballistics (Eggers et al. $)$, where a drag force $D$ is modeled that opposes the relative wind velocity $V_{\infty}$ as in:

$$
D=\frac{1}{2} C_{D} \rho V_{\infty}^{2} A
$$

where $C_{D}$ is the drag coefficient, $\rho$ is the atmospheric density, and $A$ is the reference area for the drag coefficient. The model reduces the maximum range compared to vacuum ballistics, and allows for downwind travel. The range is highly dependent on the value of the drag coefficient.

The next level of complexity has fragment rotation and translation along the trajectory, with calculation of aerodynamic forces and moments (Slegers et al., 2009). The authors' 
trajectory model is based primarily on Sørensen (1984).

Impact Probability Turner (1986) determined probability of impact around the turbine, along with the possibility of bouncing and sliding of the fragment after impact. The authors used his methods in the setback evaluation; however, several turbine sizes are considered. Like Turner, impact probability was determined with a Monte Carlo simulation of thousands of fragment throws with randomly determined inputs. A sensitivity analysis of the model was performed by varying the inputs separately. The model was insensitive to many of the parameters studied; the most important was the mass of the blade.

Probability of impact was determined for a point target and a target representing a family-size dwelling. The authors studied four turbine models of $750 \mathrm{~kW}, 1.5 \mathrm{MW}, 3.0 \mathrm{MW}$, and 5.0 MW size, with nominal blade tip speeds that correspond to current turbine models. The authors compared the models for their range that results in a 1 in 1,000,000 impact probability. Macqueen et al. (1983) provided the inspiration for this probability, which is one order of magnitude more probable than being struck by lighting in the U. K. The range for this probability increased with both model rating and tip speed. However, if the range is normalized by turbine overall height, the normalized range generally decreases with turbine rating. The change in normalized range is not very dramatic; therefore, authorities having jurisdication may prefer to retain a single setback for all sizes of turbines. 


\section{Methods}

This section summarizes the modeling as shown in Fig.1.

\subsection{Blade Failure Probability}

For the probability that a rotor failure has occurred, the authors used the analysis results from Braam et al. (2005). These resulting failure probabilities are shown in Table 1 ,

Table 1: Rotor failure probabilities from Braam et al. (2005)

\begin{tabular}{ll}
\hline Operating Condition & Probability per turbine per year \\
\hline Nominal operating rpm & $4.2 \times 10^{-4}$ \\
Braking (1.25 times nominal rpm) & $4.2 \times 10^{-4}$ \\
Emergency (2.0 times nominal rpm) & $5.0 \times 10^{-6}$ \\
\hline
\end{tabular}

Nominal operating rpm is regular operation during power production, from the lowest wind speed that the turbine turns on $(3-5 \mathrm{~m} / \mathrm{s})$ to the highest wind speed that the turbine turns off $(22-27 \mathrm{~m} / \mathrm{s})$. Braking refers to the condition when the turbine is shutting down, for any reason except an overspeed condition. Emergency refers to a rotor overspeed condition. The failure probability consists of the time spent in each operating condition along with the potential for high loads (and thus failure) at each condition. The amount of time spent in each condition decreases from nominal to emergency, but the potential for high loads increases.

The setback evaluation does not include fragment failures when the turbine is parked, such as from 50-year extreme gust. Besides being a rare event, the range from a possible failure is much lower compared to an operating failure due to release velocities below that of normal operating speeds. Ranges for this condition were determined and are shown in the Sensitivity Analysis Section 2.5. 


\section{$2.2 \quad$ Fragment Trajectory}

The analysis assumes that the rotor breaks at a radial location along the blade and the outboard portion is released, remaining in one piece. Realistic fragments would probably have breaks with rough edges that would increase drag. Therefore, the ranges in this study are considered conservative. For the trajectory the authors used the method developed by Montgomerie (1982) and further elaborated by Sørensen (1984). The analysis breaks the fragment into strips (Fig. 22), with each strip having separate aerodynamic and inertia properties. The forces are computed on each strip and then combined to determine the total forces and moments at the fragment center of mass (point $C$ ).

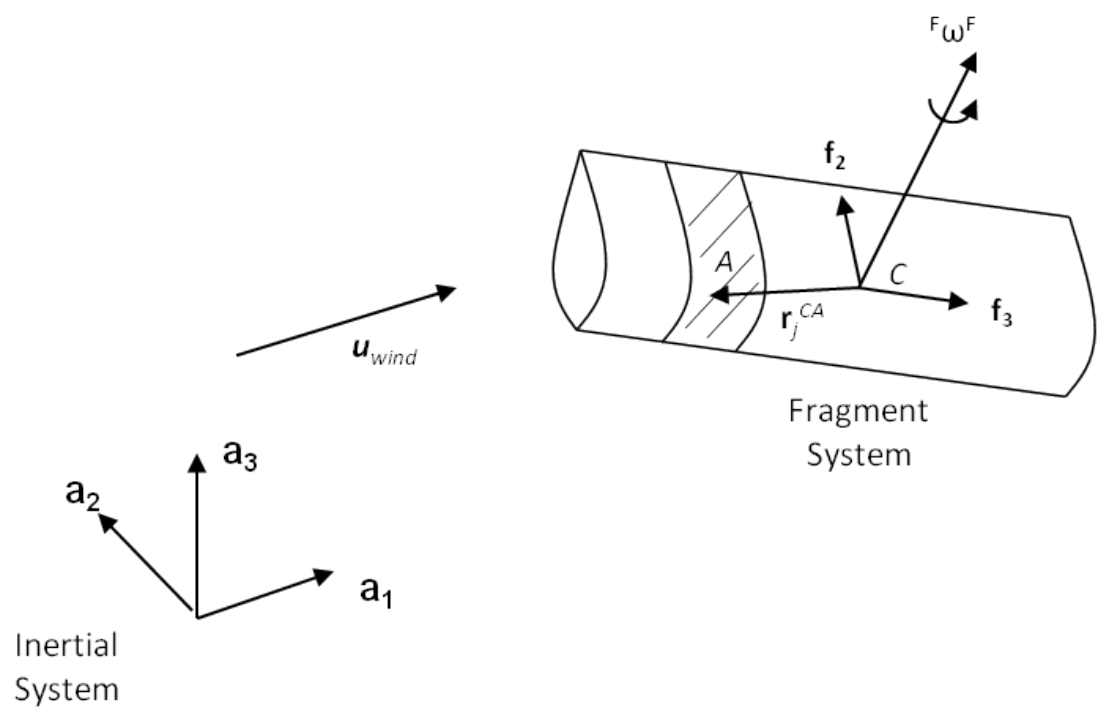

Figure 2: Blade fragment showing fragment $\mathbf{f}$ system (Body F; $\mathbf{f}_{1}$ not shown for clarity) with position vector $r_{j}^{C A}$ from the fragment mass center to the element aerodynamic center, along with the fragment angular velocity vector ${ }^{\mathrm{F}} \boldsymbol{\omega}^{\mathrm{F}}$ in the fragment $\mathbf{f}$ system

The equations of motion as a complete system of first-order differential equations are listed in three blocks below, and are similar to those in Sørensen (1984). The simulation uses a Runge-Kutta scheme to numerically solve the equations of motion. Equation block 3 represent the translational velocities and accelerations of the fragment mass center $C$ in the 
inertial frame $\mathbf{E}$ (a-system unit vectors) according to Newton's second law. Equation block 4 represent the change in the orientation matrix from the inertial frame $\mathbf{E}$ to the fragment frame $\mathbf{F}$. This formulation avoids potential singularities from using Euler angles. Equation block 5 are the Euler equations in the fragment frame $\mathbf{F}$.

$$
\begin{array}{ll}
\dot{r}_{\mathrm{a} 1}^{D C}={ }^{\mathrm{E}} v_{\mathrm{a} 1}^{C} & { }^{\mathrm{E}} \dot{\mathrm{v}}_{\mathrm{a} 1}^{C}=F_{\mathrm{a} 1}^{C} / m \\
\dot{r}_{\mathrm{a} 2}^{D C}={ }^{\mathrm{E}} v_{\mathrm{a} 2}^{C} & { }^{\mathrm{E}} \dot{v}_{\mathrm{a} 2}^{C}=F_{\mathrm{a} 2}^{C} / m \\
\dot{r}_{\mathrm{a} 3}^{D C}={ }^{\mathrm{E}} v_{\mathrm{a} 3}^{C} & { }^{\mathrm{E}} \dot{v}_{\mathrm{a} 3}^{C}=F_{\mathrm{a} 3}^{C} / m-g
\end{array}
$$

$$
\begin{aligned}
& \dot{\mathrm{T}}_{\mathrm{FE} \_11}={ }^{\mathrm{F}} \omega_{\mathrm{f} 3}^{\mathrm{F}} \mathrm{T}_{\mathrm{FE} \_21}-{ }^{\mathrm{F}} \omega_{\mathrm{f} 2}^{\mathrm{F}} \mathrm{T}_{\mathrm{FE} \_31} \\
& \dot{\mathrm{T}}_{\mathrm{FE} \_12}={ }^{\mathrm{F}} \omega_{\mathrm{f} 3}^{\mathrm{F}} \mathrm{T}_{\mathrm{FE} \_22}-{ }^{\mathrm{F}} \omega_{\mathrm{f} 2}^{\mathrm{F}} \mathrm{T}_{\mathrm{FE} \_32} \\
& \dot{\mathrm{T}}_{\mathrm{FE} \_13}={ }_{\mathrm{F}} \omega_{\mathrm{f} 3}^{\mathrm{F}} \mathrm{T}_{\mathrm{FE} \_23}-{ }_{\mathrm{F}} \omega_{\mathrm{f} 2}^{\mathrm{F}} \mathrm{T}_{\mathrm{FE} \_33} \\
& \dot{\mathrm{T}}_{\mathrm{FE} \_21}=-{ }^{\mathrm{F}} \omega_{\mathrm{f} 3}^{\mathrm{F}} \mathrm{T}_{\mathrm{FE} \_11}+{ }^{\mathrm{F}} \omega_{\mathrm{f} 1}^{\mathrm{F}} \mathrm{T}_{\mathrm{FE} \_31} \\
& \dot{\mathrm{T}}_{\mathrm{FE} \_22}=-{ }_{\mathrm{F}} \omega_{\mathrm{f} 3}^{\mathrm{F}} \mathrm{T}_{\mathrm{FE} \_12}+{ }^{\mathrm{F}} \omega_{\mathrm{f} 1}^{\mathrm{F}} \mathrm{T}_{\mathrm{FE} \_32} \\
& \dot{\mathrm{T}}_{\mathrm{FE} \_23}=-{ }^{\mathrm{F}} \omega_{\mathrm{f3}}^{\mathrm{F}} \mathrm{T}_{\mathrm{FE} \_13}+{ }^{\mathrm{F}} \omega_{\mathrm{f} 1}^{\mathrm{F}} \mathrm{T}_{\mathrm{FE} \_33} \\
& \dot{\mathrm{T}}_{\mathrm{FE} \_31}={ }^{\mathrm{F}} \omega_{\mathrm{f} 2}^{\mathrm{F}} \mathrm{T}_{\mathrm{FE} \_11}-{ }^{\mathrm{F}} \omega_{\mathrm{f} 1}^{\mathrm{F}} \mathrm{T}_{\mathrm{FE} \_21} \\
& \dot{\mathrm{T}}_{\mathrm{FE} \_32}={ }^{\mathrm{F}} \omega_{\mathrm{f} 2}^{\mathrm{F}} \mathrm{T}_{\mathrm{FE} \_12}-{ }^{\mathrm{F}} \omega_{\mathrm{f} 1}^{\mathrm{F}} \mathrm{T}_{\mathrm{FE} \_22} \\
& \dot{\mathrm{T}}_{\mathrm{FE} \_33}={ }^{\mathrm{F}} \omega_{\mathrm{f} 2}^{\mathrm{F}} \mathrm{T}_{\mathrm{FE} \_13}-{ }^{\mathrm{F}} \omega_{\mathrm{f} 1}^{\mathrm{F}} \mathrm{T}_{\mathrm{FE} \_23}
\end{aligned}
$$




$$
\begin{aligned}
& { }^{\mathrm{F}} \dot{\omega}_{\mathrm{f} 1}^{\mathrm{F}}=M_{\mathrm{f} 1}^{C} / I_{\mathrm{f} 1}^{F / C}-{ }^{\mathrm{F}} \omega_{\mathrm{f} 2}^{\mathrm{F} F} \omega_{\mathrm{f} 3}^{\mathrm{F}}\left(I_{\mathrm{f} 3}^{F / C}-I_{\mathrm{f} 2}^{F / C}\right) / I_{\mathrm{f} 1}^{F / C} \\
& { }^{\mathrm{F}} \dot{\omega}_{\mathrm{f} 2}^{\mathrm{F}}=M_{\mathrm{f} 2}^{C} / I_{\mathrm{f} 2}^{F / C}-{ }^{\mathrm{F}} \omega_{\mathrm{f} 1}^{\mathrm{F} \mathrm{F}} \omega_{\mathrm{f} 3}^{\mathrm{F}}\left(I_{\mathrm{f} 1}^{F / C}-I_{\mathrm{f} 3}^{F / C}\right) / I_{\mathrm{f} 2}^{F / C} \\
& { }^{\mathrm{F}} \dot{\omega}_{\mathrm{f} 3}^{\mathrm{F}}=M_{\mathrm{f} 3}^{C} / I_{\mathrm{f} 3}^{F / C}-{ }^{\mathrm{F}} \omega_{\mathrm{f} 1}^{\mathrm{F} F} \omega_{\mathrm{f} 2}^{\mathrm{F}}\left(I_{\mathrm{f} 2}^{F / C}-I_{\mathrm{f} 1}^{F / C}\right) / I_{\mathrm{f} 3}^{F / C}
\end{aligned}
$$

The loads on the fragment are weight and aerodynamic loads. The aerodynamic loads (lift, drag, and pitching moment) are computed at the aerodynamic centers (point $A$ ) of the individual strips. These loads are then transformed to the fragment $\mathbf{f}$ system, and then combined to determine the resulting forces $(F)$ and moments $(M)$ about the fragment mass center $C$. The loads are then transformed to the Earth a system for application into the equations of motion. The model assumes steady aerodynamics as in Sørensen (1984), who determined that unsteady effects significantly complicate the analysis for slightly reduced trajectory range. There is no aerodynamic interaction between elements and there are no effects at the ends of the fragment. In addition to the forces in the plane of the chord, the simulation includes a spanwise force with a skin friction coefficient, similiar to Turner (1989).

With some fragments the speed of rotation about the fragment long axis $\left({ }^{\mathrm{F}} \omega_{\mathrm{f} 3}^{\mathrm{F}}\right)$ would increase unbounded. This was due to a combination of airfoil pitching moment along with the moment resulting from the location of the aerodynamic center relative to the mass center. Realistically an unsteady aerodynamic phenomenon would not allow the rotation to increase unbounded. Therefore, the authors included a switch in the analysis to change the model to a purely drag ballistics model when the rotation exceeded a user input value that was proportional to the fragment inertia. 


\subsection{Fragment Impact}

The flying trajectory completes when the vertical component passes through zero. This is considered the impact point; however, the simulation reduces the impact distance to account for the size of the fragment and the height of a target.

The travel of the fragment after impact is based on models proposed by Turner (1986), which includes a model of fragment bouncing and sliding. The probability of impact with a point or target on the ground is also the same as Turner (1986).

\subsection{Model Inputs}

A given run was typically 10,000 throws with inputs from Table 2 below. The program generated random numbers with the system clock as the seed.

Table 2: Input variable probability for setback evaluation

\begin{tabular}{ll}
\hline Input Variable & Probability \\
\hline Wind speed & Rayleigh distribution between 4 and $25 \mathrm{~m} / \mathrm{s}$ \\
Blade pitch & Based on wind speed \\
Rotor rotational speed & Can be based on wind speed, but fixed \\
Rotor azimuth at break & Uniform between $0^{\circ}$ and $360^{\circ}$ \\
Blade break position & Uniform between hub radius and blade tip \\
Wind direction & Uniform between $0^{\circ}$ and $360^{\circ}$, or wind rose \\
Yaw error & Uniform between $-10^{\circ}$ and $10^{\circ}$ \\
\hline
\end{tabular}

The program also accepts inputs for a wind rose, which is a graph of the probability of a particular wind speed range from a particular compass sector. The wind rose feature can also be used to fix the simulation at a particular wind direction, which is similar in the analysis of Rogers et al. (2012). 


\subsection{Sensitivity Analysis}

Similar to Sørensen (1984), a sensitivity analysis of the model inputs was performed on a single throw of a 10 meter fragment from a 1.5 MW turbine. Additional single-throw runs were performed to determine the range of 10-meter fragment from a non-operational turbine in a 50-year gust $(70 \mathrm{~m} / \mathrm{s}$ for IEC Class I (Anonymous, 2005)). The azimuth and pitch were fixed at $90^{\circ}$ (parked) and the wind direction was changed from $0^{\circ}$ to $270^{\circ}$ in $90^{\circ}$ increments.

A sensitivity analysis was also performed on the impact probability (10,000 throw baseline) of the $1.5 \mathrm{MW}$ turbine, where the range for $1 \times 10^{-6}$ probability was determined for each run. Table 4 in the Results Section list the inputs and their settings for the analysis. The "mass multiplier" is a factor that the blade mass was multiplied by to increase or decrease the blade mass. The "mass location multiplier" was a factor that multiplied the distance between the section center of mass and pitch axis to move the center of mass forward or aft of the baseline position.

\subsection{Setback Evaluation}

The authors based the setback evaluation on the following parameters and assumptions:

- Four wind turbine models were used from a National Renewable Energy Laboratory study (Malcolm and Hansen, 2006) that represented current and future utility-scale turbines. Table 3 list the model details.

- The turbines operated at nominal tip speeds of $70 \mathrm{~m} / \mathrm{s}, 80 \mathrm{~m} / \mathrm{s}$, and $90 \mathrm{~m} / \mathrm{s}$. These values represented the range of current turbine tip speeds.

- Each set consisted of three runs of 10,000 throws each with inputs according to Table 2. The three runs were for the nominal operating rpm (corresponding to the tip speed), the emergency braking speed, and the overspeed condition as described in Table 1. 
- The average wind speed of the Rayleigh distribution for a run was $8.5 \mathrm{~m} / \mathrm{s}$, which is typical of United States wind turbine installations

- The blade pitch was $0^{\circ}$ until $10 \mathrm{~m} / \mathrm{s}$ and varied linearly to $20^{\circ}$ at $25 \mathrm{~m} / \mathrm{s}$

- Results were for point probability and for a $625 \mathrm{~m}^{2}$ target, which could represent a typical dwelling footprint

- Additional sets of runs were performed with a fixed wind direction (as in Rogers et al. (2012) ) to determine upper bound of ranges

Table 3: Turbine models used for setback evaluation

\begin{tabular}{lllll}
\hline Model & $\begin{array}{l}\text { Rated } \\
\text { Power }\end{array}$ & $\begin{array}{l}\text { Rotor } \\
\text { Radius, m }\end{array}$ & $\begin{array}{l}\text { Hub } \\
\text { Height, m }\end{array}$ & $\begin{array}{l}\text { Overall } \\
\text { Height, m }\end{array}$ \\
\hline WP750 & $750 \mathrm{~kW}$ & 23 & 60 & 83 \\
WP1500 & $1.5 \mathrm{MW}$ & 35 & 80 & 115 \\
WP3000 & $3.0 \mathrm{MW}$ & 49.5 & 119 & 168.5 \\
WP5000 & $5.0 \mathrm{MW}$ & 64 & 154 & 218 \\
\hline
\end{tabular}




\section{Results}

Figure 3 shows the trajectory and orientation in the crosswind view for a $10 \mathrm{~m}$ fragment from the baseline 1.5 MW model. As in Sørensen (1984), the initial rotation dies down after the first third of the flight with the heavy end of the fragment pointing down for the remainder. The trajectory for a drag ballistics model ( 0.15 drag coefficient) is also shown for comparison. The trajectory for a drag ballistics model with $C_{D}=0$ (vacuum) would have twice the range; therefore, using drag ballistics alone for the analysis is highly dependent on the value of $C_{D}$.

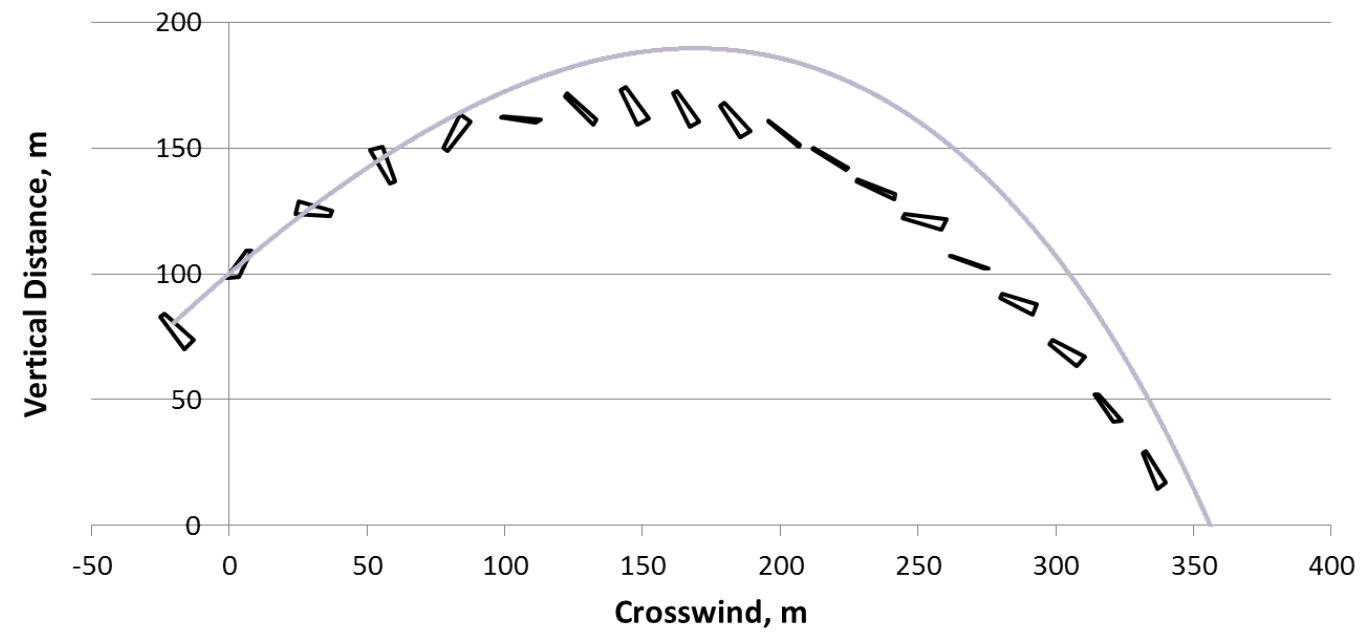

Figure 3: Full model trajectory and orientation. Line represents drag ballistics model with $C_{D}=0.15$. Baseline $1.5 \mathrm{MW}$ model, $10 \mathrm{~m}$ fragment released at $315^{\circ}$ azimuth and $26.3 \mathrm{rpm}$.

The plot on the right hand side of Fig. 1 shows the impact points for a typical 10,000 case run with a dense cloud centered around the turbine with several outliers. This is typical of all runs. Figures $4 \mathrm{a}$ and $4 \mathrm{~b}$ show scatter plots for the wind rose case and the fixed wind direction case. The wind rose is from a Northern European site with prevailing SouthSoutheast direction. The fixed wind direction case is similar in shape to a plot shown in Rogers et al. (2012). The figures do not display a uniform distribution; therefore, the risk probability will depend on the compass bearing from the turbine. 


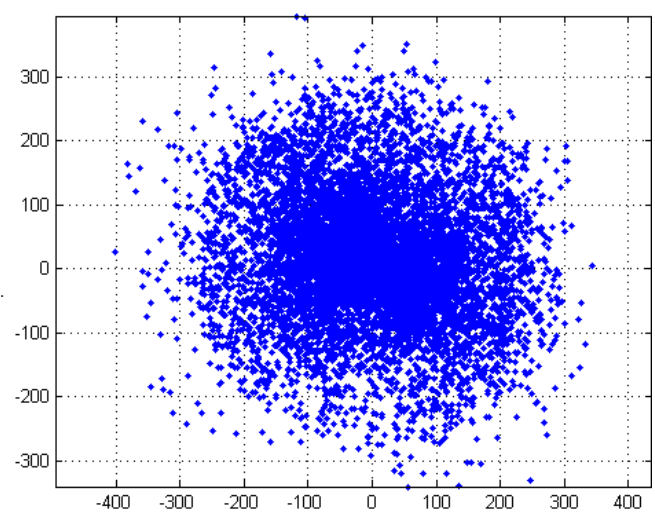

(a) WP1500 with wind rose

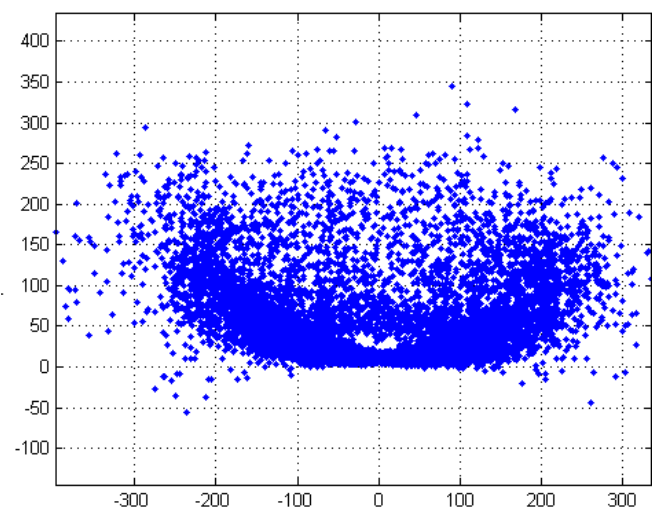

(b) WP1500 with fixed wind direction (wind from bottom)

Figure 4: Scatter plots of impacts for wind rose and fixed wind direction

Figure 5 shows a contour plot of probability for point impact, based on the impacts shown in Fig. 1. The lines of constant probability for a run are roughly circular, indicating the uniform distribution of wind direction.

\subsection{Sensitivity Analysis Results}

The outcome of the single throw sensitivity analysis was very similar to Sørensen (1984). Changing the input parameters could have a dramatic effect on the range and bearing for a single trajectory; however, over several thousand random throws the change in impact probability was mostly negligible.

The results of the 50 -year gust $(70 \mathrm{~m} / \mathrm{s})$ showed a maximum range less than one-third of the range of the baseline throw during operation. The authors therefore do not include throws from extreme wind events in the setback evaluation due to comparatively low ranges.

Table 4 shows the results of the multi-throw sensitivity analysis (Section 2.5). The analysis showed that 10,000 throws was sufficient for the range to converge for $1 \times 10^{-6}$ 


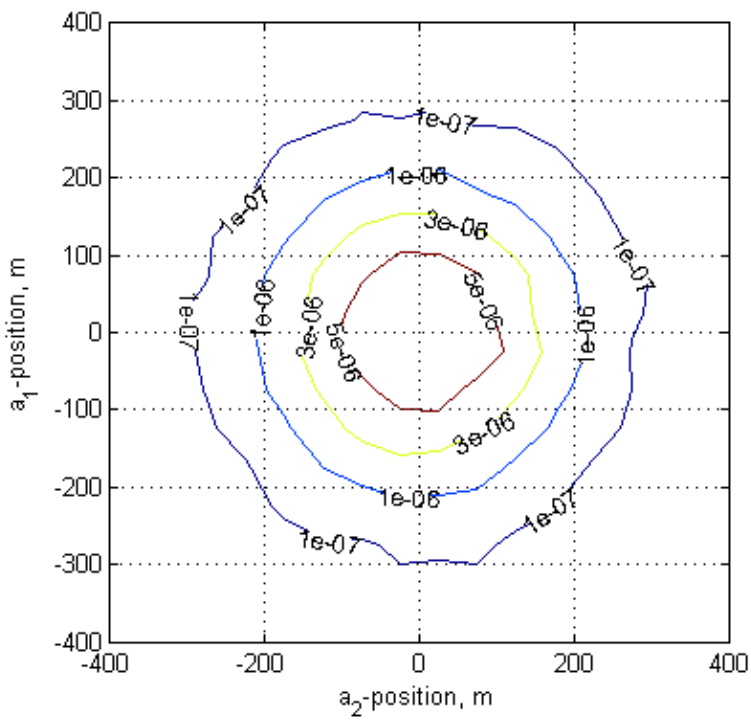

Figure 5: Point probability for WP1500 at nominal $70 \mathrm{~m} / \mathrm{s}$ tip speed

impact probability. For the range of parameters tested, several had negligible effect, such as average wind speed, hub height, altitude, and number of blade elements. Skin friction (for spanwise drag) had no effect and could be removed from the model. Increasing mass increases the range; therefore, the mass of the blade should be known. However, the baseline represents most turbines in production, and current design trends are lowering blade mass. The airfoil had no effect on the range, as long as the ballistics switch (Section 2.2) was set to 0.1 for the SERI-airfoil (has high pitching moment). In summary, the results of the baseline should be representative of most 1.5 MW wind turbine installations.

The results of the wind direction analysis showed that the assumption of uniformly distributed wind direction gives the lowest range $(215 \mathrm{~m})$ for $1 \times 10^{-6}$ impact probability, as expected. A longer range $(325 \mathrm{~m})$ is obtained with fixing the wind direction, which is similar to method of Rogers et al. (2012). The maximum range for $1 \times 10^{-6}$ impact probability increases compared to the uniform direction case because of impact concentrations within particular sectors. With a realistic wind rose, the range $(226 \mathrm{~m})$ is relatively close to the uniform wind direction range. The authors therefore conducted the setback evaluation with 
Table 4: Multi-throw sensitivity analysis results. The baseline setting is indicated by $(b)$. Baseline range for $1 \times 10^{-6}$ impact probability is $215 \mathrm{~m}$.

\begin{tabular}{|c|c|c|}
\hline Variable & Settings & Range \\
\hline Number of cases & $100 / 1 \mathrm{~K} / 5 \mathrm{~K} / 10 \mathrm{~K}(b) / 20 \mathrm{~K}$ & Converges to $215 \mathrm{~m}$ at $5 \mathrm{~K}$ \\
\hline Average wind speed & $7.5 / 8.5 / 10(b) \mathrm{m} / \mathrm{s}$ & $\begin{array}{l}\text { Respective range } \\
215 / 190 / 215 \mathrm{~m}\end{array}$ \\
\hline Hub height & $54 / 60(b) / 66 \mathrm{~m}$ & No change in range \\
\hline Time step & $\begin{array}{l}0.05 / 0.01 / 0.005(b) \\
/ 0.001 \mathrm{~s}\end{array}$ & $\begin{array}{l}\text { Unstable at } 0.05 \text {, } \\
\text { else no change }\end{array}$ \\
\hline Density (altitude) & $0(b) / 1000 / 2000 \mathrm{~m}$ & No change in range \\
\hline Ballistics switch & $\begin{array}{l}0.1 / 0.5 / 0.9 / 1.0(b) / \\
1.1 / 2.0 / 10.0\end{array}$ & $\begin{array}{l}\text { Unstable at } 10 \text {, } \\
\text { else no change }\end{array}$ \\
\hline Ballistics $C_{D}$ & $\begin{array}{l}0.1 / 0 / 7 / 1.2 / / 1.35(b) / \\
1.5 / 2.7 / 13.5\end{array}$ & No change in range \\
\hline $\begin{array}{l}\text { Airfoil } \\
\text { section data }\end{array}$ & NACA(b)/SERI/flat/Go420 & $\begin{array}{l}\text { See text for SERI, } \\
\text { else no change }\end{array}$ \\
\hline $\begin{array}{l}\text { Number of } \\
\text { blade elements }\end{array}$ & $10 / 15(b) / 20 / 30$ & No change in range \\
\hline Mass multiplier & $0.5 / 0.9 / 1.0(\mathbf{b}) / 1.1 / 2.0$ & $\begin{array}{l}\text { Respective range } \\
190 / 190 / 215 / 215 / 226 \mathrm{~m}\end{array}$ \\
\hline $\begin{array}{l}\text { Mass location } \\
\text { mulitplier }\end{array}$ & $0.9 / 1.0(b) / 1.1$ & No change in range \\
\hline Skin friction coeff. & $0.0 / 0.002(b) / 0.02$ & No change in range \\
\hline $\begin{array}{l}\text { Wind direction } \\
\text { probability }\end{array}$ & fixed/uniform $(b) /$ rose & $\begin{array}{l}\text { Respective range } \\
325 / 215 / 226 \mathrm{~m}\end{array}$ \\
\hline
\end{tabular}


both uniform wind direction and fixed wind direction, noting that the fixed wind direction results are a conservative upper bound. A realistic site would have a range close to the uniform results.

\subsection{Setback Evaluation}

Figure 6a show absolute distance for $1 \times 10^{-6} / \mathrm{y}$ probability of impacting a point. The distances increase with turbine rating and nominal tip speed. The turbines have the same tip velocities and conceivably should have similar range. However, higher fragment inertia for larger turbines results in longer ranges, which was indicated in the sensitivity analysis for mass. Figure $6 \mathrm{~b}$ shows the distance as a multiple of overall turbine height for $1 \times 10^{-6} / \mathrm{y}$ probability of impacting a point. The distance as a multiple of overall height, in general, decreases with turbine rating.

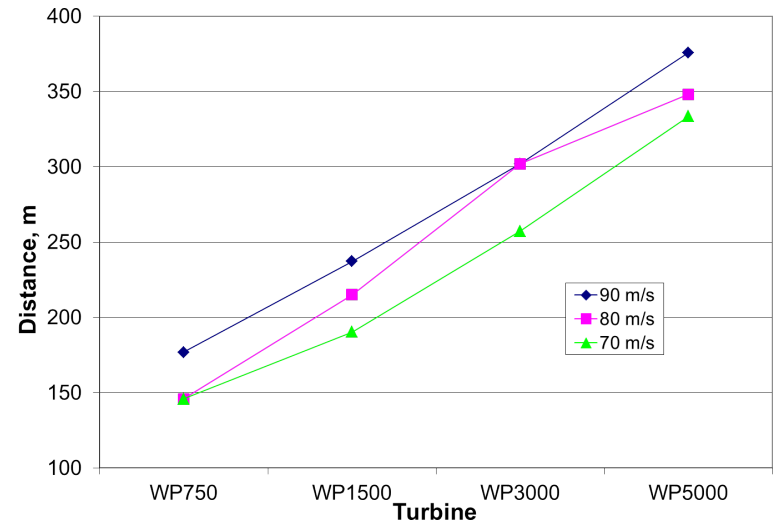

(a) Distance in meters

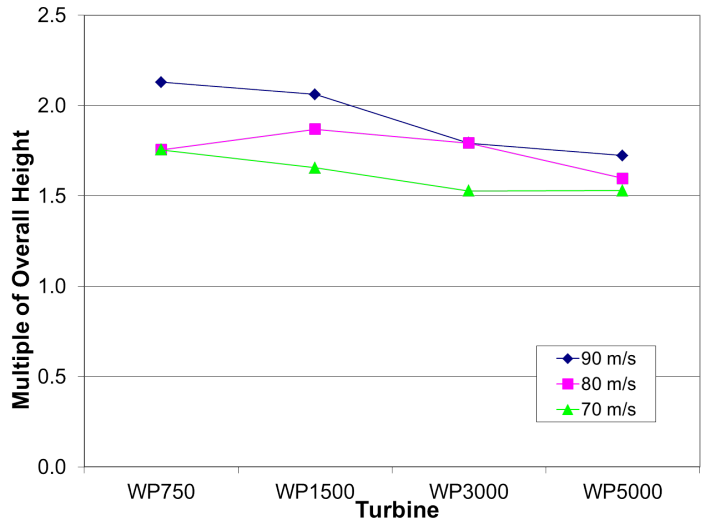

(b) Distance as a multiple of overall height

Figure 6: $1 \times 10^{-6} / \mathrm{y}$ probability of impacting a point

Table 5 summarizes the results for $1 \times 10^{-6} / \mathrm{y}$ fragment impact probability in terms of absolute distance and multiple of overall height. The values for the fixed wind direction case are in parentheses, and are greater than the uniform wind direction by 0.3-0.6 multiples of overall height. 
Table 5: Distance for $1 \times 10^{-6} / \mathrm{y}$ probability from risk analysis, with fixed wind direction results in parentheses

\begin{tabular}{|c|c|c|c|c|c|}
\hline \multirow[t]{2}{*}{ Model } & \multirow{2}{*}{$\begin{array}{l}\text { Nominal } \\
\text { Tip Speed } \\
\text { m/s }\end{array}$} & \multicolumn{2}{|c|}{ Point } & \multicolumn{2}{|c|}{$625 \mathrm{~m}^{2}$ Target } \\
\hline & & $\begin{array}{l}\text { Distance } \\
\mathbf{m}\end{array}$ & $\begin{array}{l}\text { Multiple } \\
\text { of Height }\end{array}$ & $\begin{array}{l}\text { Distance } \\
\text { m }\end{array}$ & $\begin{array}{l}\text { Multiple } \\
\text { of Height }\end{array}$ \\
\hline \multirow[t]{3}{*}{ WP750 } & 70 & $146(176)$ & $1.8(2.1)$ & $257(302)$ & $3.1(3.6)$ \\
\hline & 80 & $146(190)$ & $1.8(2.3)$ & $276(302)$ & $3.3(3.6)$ \\
\hline & 90 & $177(226)$ & $2.1(2.7)$ & $285(325)$ & $3.4(3.9)$ \\
\hline \multirow[t]{3}{*}{ WP1500 } & 70 & $190(257)$ & $1.7(2.2)$ & 334 (369) & $2.9(3.2)$ \\
\hline & 80 & $215(285)$ & $1.9(2.5)$ & $355(382)$ & $3.1(3.3)$ \\
\hline & 90 & $237(285)$ & $2.1(2.5)$ & $376(431)$ & $3.3(3.7)$ \\
\hline \multirow[t]{3}{*}{ WP3000 } & 70 & $257(333)$ & $1.5(2.0)$ & $443(432)$ & $2.6(2.6)$ \\
\hline & 80 & $302(348)$ & $1.8(2.1)$ & $437(437)$ & $2.6(2.6)$ \\
\hline & 90 & $302(382)$ & $1.8(2.3)$ & $476(475)$ & $2.8(2.8)$ \\
\hline \multirow[t]{3}{*}{ WP5000 } & 70 & 334 (395) & $1.5(1.8)$ & $481(506)$ & $2.2(2.3)$ \\
\hline & 80 & $348(431)$ & $1.6(2.0)$ & $506(580)$ & $2.3(2.7)$ \\
\hline & 90 & $376(443)$ & $1.7(2.0)$ & $567(637)$ & $2.6(2.9)$ \\
\hline
\end{tabular}

Figure 7 shows the probability of impacting a point versus multiple of turbine height for $70 \mathrm{~m} / \mathrm{s}$ and $90 \mathrm{~m} / \mathrm{s}$ tip speeds. The probability for impacting a $625 \mathrm{~m}^{2}$ target is approximately one order of magnitude higher. The plots show the value and slope of the probability decreasing as the turbine size increases. The data from these figures including target probabilities and fixed wind direction probabilities is listed in Table 6 . 
Table 6: Probability of impact for multiples of turbine height. Point probability is in first row, target probability is in second row. Fixed wind direction probabilities are in parenthesis.

\begin{tabular}{|c|c|c|c|c|}
\hline \multicolumn{2}{|c|}{$\begin{array}{l}\text { Model } \\
\text { and tip } \\
\text { speed } \mathrm{m} / \mathrm{s}\end{array}$} & $\begin{array}{l}\text { aseline } \\
\text { eight }\end{array}$ & $\begin{array}{l}\times \text { Baseline } \\
\text { leight }\end{array}$ & $\begin{array}{l}3 \times \text { Baseline } \\
\text { Height }\end{array}$ \\
\hline 0 & 80 & $\begin{array}{ll}4.0 \cdot 10^{-6} & \left(1.1 \cdot 10^{-5}\right) \\
1.0 \cdot 10^{-4} & \left(2.9 \cdot 10^{-4}\right) \\
3.6 \cdot 10^{-6} & \left(1.1 \cdot 10^{-5}\right) \\
9.3 \cdot 10^{-5} & \left(2.7 \cdot 10^{-4}\right) \\
3.7 \cdot 10^{-6} & \left(9.9 \cdot 10^{-6}\right) \\
9.5 \cdot 10^{-5} & \left(2.6 \cdot 10^{-4}\right)\end{array}$ & $\begin{array}{l}7.1 \cdot 10^{-7}\left(2.6 \cdot 10^{-6}\right) \\
1.8 \cdot 10^{-5}\left(6.7 \cdot 10^{-5}\right) \\
9.1 \cdot 10^{-7}\left(2.6 \cdot 10^{-6}\right) \\
2.3 \cdot 10^{-5}\left(6.7 \cdot 10^{-5}\right) \\
1.1 \cdot 10^{-6}\left(3.6 \cdot 10^{-6}\right) \\
2.8 \cdot 10^{-5}\left(9.2 \cdot 10^{-5}\right)\end{array}$ & $\begin{array}{ll}3.2 \cdot 10^{-8} & \left(8.5 \cdot 10^{-8}\right) \\
8.2 \cdot 10^{-7} & \left(2.2 \cdot 10^{-6}\right) \\
8.8 \cdot 10^{-8} & \left(1.2 \cdot 10^{-7}\right) \\
2.6 \cdot 10^{-6} & \left(3.0 \cdot 10^{-6}\right) \\
1.5 \cdot 10^{-7} & \left(1.8 \cdot 10^{-7}\right) \\
3.9 \cdot 10^{-6} & \left(4.5 \cdot 10^{-6}\right)\end{array}$ \\
\hline WP & 70 & $\begin{array}{l}5.1 \cdot 10^{-6}\left(9.1 \cdot 10^{-6}\right) \\
1.3 \cdot 10^{-4}\left(2.4 \cdot 10^{-4}\right) \\
4.5 \cdot 10^{-6}\left(5.5 \cdot 10^{-6}\right) \\
1.2 \cdot 10^{-4}\left(1.4 \cdot 10^{-4}\right) \\
4.0 \cdot 10^{-6}\left(3.4 \cdot 10^{-6}\right) \\
1.0 \cdot 10^{-4}\left(8.8 \cdot 10^{-5}\right)\end{array}$ & $\begin{array}{l}6.6 \cdot 10^{-7}\left(2.8 \cdot 10^{-6}\right) \\
1.7 \cdot 10^{-5}\left(7.2 \cdot 10^{-5}\right) \\
9.2 \cdot 10^{-7}\left(4.3 \cdot 10^{-6}\right) \\
2.4 \cdot 10^{-5}\left(1.1 \cdot 10^{-4}\right) \\
1.3 \cdot 10^{-6}\left(6.7 \cdot 10^{-6}\right) \\
3.2 \cdot 10^{-5}\left(1.7 \cdot 10^{-4}\right)\end{array}$ & $\begin{array}{l}1.7 \cdot 10^{-8}\left(5.1 \cdot 10^{-8}\right) \\
4.4 \cdot 10^{-7}\left(1.3 \cdot 10^{-6}\right) \\
4.0 \cdot 10^{-8}\left(1.1 \cdot 10^{-7}\right) \\
1.0 \cdot 10^{-6}\left(2.8 \cdot 10^{-6}\right) \\
6.3 \cdot 10^{-8}\left(2.3 \cdot 10^{-7}\right) \\
1.6 \cdot 10^{-6}\left(6.0 \cdot 10^{-6}\right)\end{array}$ \\
\hline & 70 & $\begin{array}{l}4.9 \cdot 10^{-6}\left(1.5 \cdot 10^{-5}\right) \\
1.3 \cdot 10^{-4}\left(3.8 \cdot 10^{-4}\right) \\
4.1 \cdot 10^{-6}\left(1.6 \cdot 10^{-5}\right) \\
1.1 \cdot 10^{-4}\left(4.2 \cdot 10^{-4}\right) \\
3.9 \cdot 10^{-6}\left(1.6 \cdot 10^{-5}\right) \\
1.0 \cdot 10^{-4}\left(4.0 \cdot 10^{-4}\right)\end{array}$ & $\begin{array}{l}2.8 \cdot 10^{-7}\left(1.3 \cdot 10^{-6}\right) \\
7.1 \cdot 10^{-6}\left(3.2 \cdot 10^{-5}\right) \\
5.4 \cdot 10^{-7}\left(1.9 \cdot 10^{-6}\right) \\
1.4 \cdot 10^{-5}\left(4.9 \cdot 10^{-5}\right) \\
6.5 \cdot 10^{-7}\left(2.4 \cdot 10^{-6}\right) \\
1.7 \cdot 10^{-5}\left(6.0 \cdot 10^{-5}\right)\end{array}$ & $\begin{array}{l}6.9 \cdot 10^{-10}\left(1.9 \cdot 10^{-9}\right) \\
2.6 \cdot 10^{-7}\left(4.9 \cdot 10^{-8}\right) \\
1.8 \cdot 10^{-9}\left(5.6 \cdot 10^{-9}\right) \\
4.5 \cdot 10^{-8}\left(1.4 \cdot 10^{-7}\right) \\
2.1 \cdot 10^{-9}\left(7.8 \cdot 10^{-9}\right) \\
5.4 \cdot 10^{-8}\left(2.0 \cdot 10^{-7}\right)\end{array}$ \\
\hline 00 & 70 & $\begin{array}{l}5.5 \cdot 10^{-6}\left(1.4 \cdot 10^{-5}\right) \\
1.4 \cdot 10^{-4}\left(3.7 \cdot 10^{-4}\right) \\
4.9 \cdot 10^{-6}\left(1.1 \cdot 10^{-8}\right) \\
1.3 \cdot 10^{-4}\left(2.7 \cdot 10^{-4}\right) \\
4.0 \cdot 10^{-6}\left(7.6 \cdot 10^{-6}\right) \\
1.0 \cdot 10^{-4}\left(2.0 \cdot 10^{-4}\right)\end{array}$ & $\begin{array}{l}1.2 \cdot 10^{-7}\left(1.6 \cdot 10^{-7}\right) \\
3.2 \cdot 10^{-6}\left(4.1 \cdot 10^{-6}\right) \\
2.3 \cdot 10^{-7}\left(2.5 \cdot 10^{-7}\right) \\
6.0 \cdot 10^{-6}\left(6.5 \cdot 10^{-6}\right) \\
4.1 \cdot 10^{-7}\left(1.8 \cdot 10^{-7}\right) \\
1.1 \cdot 10^{-5}\left(4.7 \cdot 10^{-6}\right)\end{array}$ & $\begin{array}{l}2.3 \cdot 10^{-10}\left(1.1 \cdot 10^{-10}\right) \\
5.8 \cdot 10^{-9}\left(2.7 \cdot 10^{-9}\right) \\
8.2 \cdot 10^{-10}\left(2.1 \cdot 10^{-9}\right) \\
1.2 \cdot 10^{-8}\left(5.3 \cdot 10^{-8}\right) \\
1.7 \cdot 10^{-9}\left(6.1 \cdot 10^{-9}\right) \\
4.4 \cdot 10^{-8}\left(1.6 \cdot 10^{-7}\right)\end{array}$ \\
\hline
\end{tabular}




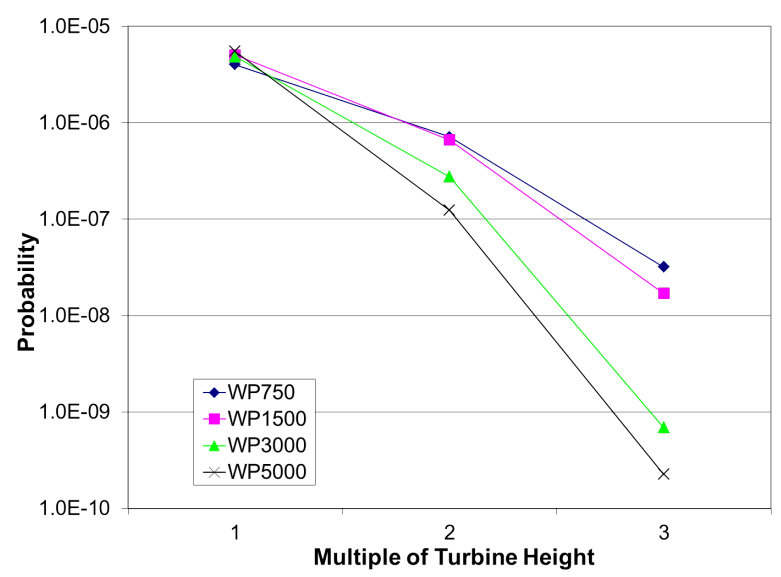

(a) Nominal tip speed $70 \mathrm{~m} / \mathrm{s}$

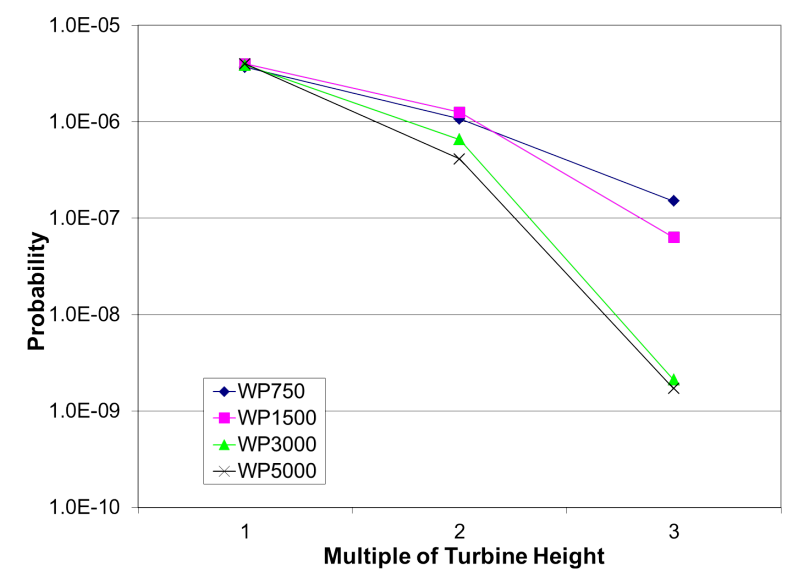

(b) Nominal tip speed $90 \mathrm{~m} / \mathrm{s}$

Figure 7: Probability of impacting a point versus multiple of overall height 


\section{Conclusions}

The authors have developed a model to determine the probability of impact from wind turbine fragments at specific distances from the turbine. Authorities having jurisdiction can use the results from this work to develop, evaluate, and revise wind turbine setbacks. The results show that if the setback is based on a multiple of overall turbine height, the probability of impact decreases as the wind turbine rating increases (larger turbines).

Although there may be benefit to using fixed distances for setbacks depending on turbine rating and tip speed, it would be simpler to continue to use setbacks as a function of overall turbine height. It would be logical to change this approach if the decrease in risk with turbine rating was more dramatic. For an allowable $1 \times 10^{-6} / \mathrm{y}$ impact probability, a setback of two overall heights to a property line and three overall heights to a dwelling may be reasonable. This is similar to ordinances reported in Larwood and van Dam (2006). Setbacks approaching one turbine height would have an order of magnitude increase in impact probability.

The trajectory model showed good agreement with Sørensen (1984). Individual trajectories were sensitive to the input parameters. However, setbacks determined from multiple throws are not sensitive to inputs except for blade mass. The effect of spanwise drag was negligible and could be removed from modeling. Parked turbines/extreme winds do not need to be included. The setbacks are sensitive to the wind direction probability; however, a realistic distribution was shown to be very close to a uniform distribution.

Data from actual failures and experimental studies can be used to validate the modeling approach taken here. Validation with an actual failure can be made with information regarding the operating conditions (Table 2), the range/direction of impact, and the geometric/mass properties of the fragment. Experimental studies should include realistic translational and rotational velocity at release. One approach would be to deliberately cause a rotor failure on a turbine at the end of its useful life in a clear field. Explosive bolts or a ring 
charge could be used to separate the blade or fragment from the turbine. The azimuth at break must be carefully determined. Another approach would be to launch fragments from a catapult. 


\section{References}

Anonymous. Wind turbines - Part 1: Design Requirements. IEC 61400-1 Ed. 3, International Electrotechnical Commission, Switzerland, 2005.

H. Braam, G. van Mulekom, and R. Smit. Handboek Risicozonering Windturbines. Technical report, SenterNovem, Netherlands, 2005.

A. J. Eggers, W. Holley, R. Digumarthi, and K. Chaney. Exploratory Study of HAWT Blade Throw Risk to Nearby People and Property. In 2001 ASME Wind Energy Symposium, number AIAA-2001-0061, Reno, Nevada, U.S.A.

A. F. Fritzsche. The Health Risks of Energy Production. Risk Analysis, 9(4):565-577, 1989.

P. Gipe. Wind Energy Comes of Age. John Wiley \& Sons, Inc., Hoboken, New Jersey, U.S.A., 1995.

M. H. Huesemann. The limits of technological solutions to sustainable development. Clean Technologies and Environmental Policy, 5(1):21-34, 2003.

S. Larwood and C. van Dam. Permitting Setback Requirements for Wind Turbines in California. CEC-500-2005-184, California Energy Commission, Sacramento, California, U.S.A., 2006.

N. Lin and E. Vanmarcke. Windborne debris risk assessment. Probabilistic Engineering Mechanics, 23:523-530, 2008.

J. F. Macqueen, J. F. Ainsilie, D. M. Milborrow, D. M. Turner, and P. D. Swift-Hook. Risks associated with wind-turbine blade failures. IEE Proceedings, 130(9):574-586, 1983.

D. J. Malcolm and A. C. Hansen. WindPACT Turbine Rotor Design Study June 2000-June 
2002. NREL/SR-500-32495, National Renewable Energy Laboratory, Golden, Colorado, U.S.A, April 2006.

B. Montgomerie. Horizontal Axis Wind Turbine Blade Failure, Blade Fragment Six Degrees of Freedom Trajectory, Site Risk Level Prediction. In Fourth International Symposium on Wind Energy Systems, volume 2, pages 389-401, Stockholm, Sweden, 1982. BHRA Fluid Engineering.

M. Nyberg. Total Electricity System Power, last accessed: 27 May 2014. URL www. energyalmanac.ca.gov/electricity/total_system_power.html.

M. O. Ramoni and H.-C. Zhang. End-of-life (EOL) issues and options for electric vehicle batteries. Clean Technologies and Environmental Policy, 15(6):881-891, 2013.

J. Rogers, N. Slegers, and M. Costello. A method for defining wind turbine setback standards. Wind Energy, 15(2):289-303, 2012.

N. Slegers, J. Rogers, M. Costello, M. Puga, and P. Arons. Modeling the Risk of a Failed Wind Turbine Blade Impacting a Power Transmission Line. Wind Engineering, 33(6): 587-606, 2009.

J. N. Sørensen. On the calculation of trajectories for blades detached from horizontal axis wind turbines. Wind Engineering, 8(3):160-175, 1984.

D. M. Turner. A Monte Carlo Method for Determining the Risk Presented by Wind Turbine Blade Failures. Wind Engineering, 11(1):1-20, 1986.

D. M. Turner. An analysis of blade throw from wind turbines. In P. D. Swift-Hook, editor, Wind Energy and the Environment, pages 112-135. Peter Peregrinus, Ltd., London, 1989.

R. Wiser and M. Bolinger. 2012 Wind Technologies Market Report. Technical report, U. S. Department of Energy, Washington, D.C., U.S.A., 2013. 